\title{
Retraction Note: Research on rain slope stability and digital village construction in mountainous areas based on remote sensing images
}

\author{
Fengju Cheng ${ }^{1}$. Jingzhao Zhang ${ }^{2}$
}

Published online: 15 December 2021

C) Saudi Society for Geosciences 2021

Retraction Note: Arabian Journal of Geosciences (2021) 14: 1881

https://doi.org/10.1007/s12517-021-08165-1

The Editor-in-Chief and the Publisher have retracted this article because the content of this article is nonsensical. The peer review process was not carried out in accordance with the Publisher's peer review policy. The authors have not responded to correspondence regarding this retraction.

The original article can be found online at https://doi.org/10.1007/ s12517-021-08165-1.

Jingzhao Zhang

jiutan1513@163.com

1 Qingdao Huanghai University, Qingdao 266427, Shandong, China

2 Shandong GEO-Surveying \& Mapping Institute, Jinan 250000, Shandong, China 